\title{
The initial training for educators in Early Childhood Education and Care in Italy: normative and curricular aspects
}

Arianna Taddej ${ }^{1}$

\begin{abstract}
The quality of educational services for children depends structurally on the professional competence of the educators who work in them: such skills may develop within the services; however, they are mostly linked with the training itineraries that lead to practising the profession. Recent norms made mandatory an initial university training program within the undergraduate class L-19 for educators for children aged from zero to three. This norm found out that universities are at least partially equipped for the ensuing training challenge; however, a wide range of different offers marks the context. The paper, starting from a short reconnaissance of the existing norms, finds the essential characteristics that should appear in a possible academic curriculum for early childhood educators, it is based on hypotheses put forward in recent months. Such hypothesis is then compared with the present reality of the undergraduate courses in Italy within the class L-19, finding the coherence and the reasons for problems in the relationship between the state of things and the new request for training for the courses of this sector.
\end{abstract}

Keywords: University, training, educators, early childhood educational services.

\section{An overview of the norms in Italy: toward a curriculum for educators for early childhood services}

Presently, the professional profile of the educator in the early childhood educational services (age 0 to 3 ) shows very diversified training requirements: in fact, until now no academic title was necessary with the exception of some regions, it was enough to obtain a diploma in some specific types of high school. Starting in the 2000s, with the reform of the undergraduate courses

\footnotetext{
${ }^{1}$ Arianna Taddei, Researcher on Didactics and Special Pedagogy, Department of Education, Cultural Heritage and Tourism, University of Macerata.

${ }^{2}$ L-19 class corresponds to three year undergraduate courses in Educational Sciences and Training.
} 
in Educational Sciences, Universities began to take specific interest on the training of the educators for the nurseries, implementing training itineraries of a different nature but still rich in skills, they vary within the field of training sciences with reference to disciplinary sectors like the pedagogical, psychological and socio-anthropological ones (Lazzari, Picchio \& Balduzzi, 2015). Considering this and the historical process of evolution that concerned the educational services for early childhood ${ }^{3}$, the general overview on training educators seems complex and causes an unavoidable reflection on the typology of skills needed to guarantee the quality of the educational offer. Such reflection is obviously placed within the Italian and international political and cultural contexts.

As highlighted by the publication by the European Commission-EACEAEurydice-Eurostat (2014) and the research in the fields of education and training (Peeters, 2008; Urban, 2008; Pirard, 2011), the question of the professionalism of the educational services for children seems to be urgent for institutional and socio-cultural reasons. As already proved by many studies on the subject, the overall quality of the educational services is strongly dependent on the quality of the professional resources that work in them, as specifically underlined by an interesting study published in 2011, commissioned by the European Commission Directorate-General for Education and Culture. What does it mean to make an educator competent in an increasingly "demanding" context for educational professions in relation to children, parents and communities? Are different routes possible within diversified but in themselves coherent policies that aim to continuous professional development starting from initial (academic) learning and lifelong learning, the latter accomplished with specialised professionals (university researchers, pedagogical coordinators, psychological counsellors, experts of the social and health service sectors, among others). The perspectives spread at European level (Urban et al., 2012; Peeters et al., 2016) show that the competence of an ECEC (Early Childhood Education and Care) system develops through four dimensions present in the system: individual level, institutional and collegial level, inter-institutional level and finally at the governance level. Therefore, it is a concept of competence that "overtakes" the traditional meaning, prevalently linked with the acquisition of knowledge and individual skills, adopting instead a holistic interpretation of "competence" developed through the different levels of the system that characterise the complexity of the educational work. Inside this frame, the

\footnotetext{
${ }^{3}$ Within the vast literature on the subject see also: Caroli D. (2014). Per una storia dell'asilo nido in Europa tra Ottocento e Novecento. Milano: FrancoAngeli; OECD (2006). Starting Strong II: Early Childhood Education and Care. Paris, France: Organisation for Economic Development.
} 
concept of competence is expressed through the dimension of knowledge, practices and values: in particular, practice as a process to reflect in order to produce an apprenticeship to be shared among all who are involved in working in educational activity (Wenger, 1998); finally, the values are not assumed on the basis of the individual sensitivity or choices but are based on the vision of early childhood education built on collective goals and aspirations.

In relation to the progress made in our Country, the cultural and pedagogical debate on training the educators for early childhood services is confirmed, to present days, in the university offer with different types of answers in the undergraduate courses that refer to class L-19. These are generic courses, courses dedicated exclusively to the training for the educators for age zero to three and specific curricula inside specific undergraduate courses. To resolve such a scenario intervenes the normative guideline in the legislative Decree number 65 of 13 April 2017 "Institution of the integrated system of education and learning from birth to the age of six" implementing law n.107 of 13 July 2015 "Reforms the national system of learning and training and delegates the reorganisation of the existing legislative norms". Such decree highlights the need to foresee "university qualifications and the continuous training of the educational services personnel for children and for childhood schooling".

The Decree states:

As from the schooling year 2019/2020 the access to the posts as educators for educational services and children is permitted exclusively to those who hold the three-year degree in Educational Sciences in class L.19 addressing specifically educators for childhood educational services and the single circle five-year degree in primary Learning Sciences, integrated with a specialisation course for a total of 60 university training credits. The titles obtained within specific regional norms continue to be valid for the access to posts as educators for childhood services, should they not be correspondent to those mentioned above and obtained before the date of implementation of the present decree (Art. 14, comma 3).

Concerning the implementation of the normative dictation to produce a specific curricular proposal, two proposals were forwarded during this last year, their main points of convergence and differentiation will be briefly commented below: the first proposal is contained in the amendment then forwarded to the Senate by Senator Puglisi in relation to the Bill 2443 (known as Iori's law), while the second was presented by MIUR (Ministry of Education, Universities and Research) to CUN (University National Council) obtaining an overall positive reception (CUN, 29/11/2017). Both proposals, which contemplate 60 academic credits, are strongly oriented to develop competences in the psycho-pedagogical and didactic areas, and in the methodological, linguistic, 
sociological and preventive ones. Both of them require the adoption of a didactic approach that, along with some traditional methods, meets the varied teachings with active laboratory strategies (among them, case analysis, observation experiences, research strategies), while it stresses the centrality of internship and requires the completion of a project work centred on the internship and on the themes linked with early childhood education. One main difference between the two proposals concerns the different quantitative dimension of the single scientific-disciplinary sectors. In short, the pedagogical components receive respectively: 24/30 university credits (UTC - University Training Credits) in Puglisi's proposal and 32/48 UTC in MIUR's proposal, while for the psychological components the two proposal reserve from 8 to 16 UTC. The workshops are set to receive from 3 to 12 credits in the first case, and from 8 to 12 in the second. Concerning the internship, Puglisi's proposal contemplates from 4 to 9 UTC, while MIUR's proposal has 4 credits for the direct internship and from 4 to 6 for indirect internship. Finally, apart from possible polarisations deriving from different implementations of the above ranges, the two proposals are substantially homogeneous.

\section{The present training offer in the Italian Universities in L-19 class: some quanti- tative and qualitative data}

A recent study on "Initial training of early childhood educators. Reality and perspectives" (Restiglian, 2017) proposes the panorama of the courses in class 19 that according to Legislative Decree 65/2017 must assume, in Italy, the training of early childhood educators. This research shows that the training offer for the Academic year 2016-2017 as shown on the site Universitaly, offers 47 courses in class L-19 in 41 universities (some universities have activated more than one course within L-19 class, in Bologna, Padua and Roma Tre) of different typologies: public, private and online. As specified in the publication, the analysis regarded only the courses that, in the parts of the briefing card published on the site analysed, are called "The course in short" and "Employment and professional opportunities for the graduates", included the area of early childhood education in the services for children, for children and parents, parenthood support and others" (Restiglian, 2017, p. 8).

The analysis of the 47 courses showed the presence of the three types of training offers mentioned above:

- Two specific L-19 courses for the profession of educators in childhood educational services: "Educators in childhood services" at the University of Bologna and "Educators for childhood and social integration" at LUMSA University in Rome. 
- L-19 courses that show a specific curriculum. Despite the difficulty to fully understand the indications given by the different institutions, we can identify 11 Universities with this specific curricula.

- Generic L-19 courses. Considering that here too we can find intermittent teachings addressing early childhood, we can affirm that the courses that do not address specifically such theme are 34 .

The overview of the educational offer related to L-19 appears generally varied and has many different shades. In short, starting from a quantitative reading based on the data gathered in the above study for each university, we find the following situation:

- Concerning the teachings of pedagogical area, several teaching titles were recorded: 62 in general and social Pedagogy (from family contexts to work, interculturalism, training, communication, differences, media); 28 in History of Pedagogy (from school historical perspective, educational institutions and compared history to history of childhood and childhood literature), 61 in Didactics and Special Pedagogy (including the methodological components of the educational action, including the team working techniques, the theme of disability and inclusion, marginality and deviance and Information Communication Technology) and 24 in Experimental Pedagogy (referable to contexts that mostly concern evaluation, educational research and quality insurance). In general, at the national level the offer in the pedagogical area seems to be very diversified.

- Concerning the area of psychology the differentiation of the available teachings is much more reduced. The total number of titles concerns the eight sectors of psychology and follow the general denomination of the sectors. The three most frequent teachings are those of general psychology (31), psychology of development (35) and social psychology (18).

- The same observation can be made for sociology. It presents six scientificdisciplinary sectors with 31 teachings in general sociology and 20 in sociology of cultural and communication processes.

- Cultural anthropology is present with varied denominations in 16 Universities.

In most of the Universities, in particular, in those with generic courses, the student is often allowed to make choices that can be consistent. For this purpose, we should not forget that the professional opportunities for the students attending class 19 preparation are numerous and very diversified. Therefore, the risk of not developing adequate knowledge and skills for the function of educator for early childhood services is real, especially in those courses that do not appear to have a specific address. Concerning pedagogical disciplines, as reported in the study, general courses go from the 40 UTC of Cusano online University to 114 UTC in Florence or, taking into account 
the overall offers from campuses that allow to personalise the plans of study for early childhood sector - as in the cases of Brescia (Cattolica University), Milano (Cattolica University), and Roma Tre - we can attain respectively 130, 135 and 180 credits in the pedagogical area. The situation is even more critical for the psychology sectors (where we go from 0 credits in Chieti-Pescara to 42 in Cusano E-campus) and for sociology (where we go from zero credits in the campuses of Chieti-Pescara, Rome Sapienza, E-campus Pegaso, to 45 in L'Aquila).

The same situation of inhomogeneity relates also to the quantity of credits that were much less consistent with the plans of study, it concerns the disciplines of the medical sector and of the disciplinary didactics.

\section{University training for early childhood educators in L-19 class}

As seen above, Restiglian highlights that only two universities at national level propose a specifically tailored undergraduate course: the University of Bologna and LUMSA University in Rome. The analysis of the differences between the two courses brings out some rather meaningful elements, as shown in the table below (Table 1).

Table 1 - University training credits (UTC) for disciplinary areas for undergraduate courses dedicated to educators for age 0 to 3

\begin{tabular}{|l|c|c|}
\hline Disciplinary Areas & $\begin{array}{c}\text { Bologna University } \\
\text { (UTC) }\end{array}$ & $\begin{array}{c}\text { LUMSA University } \\
\text { (UTC) }\end{array}$ \\
\hline Pedagogical Area & 64 & 48 \\
\hline Psychological Area & 24 & 27 \\
\hline Sociological Area & 16 & 15 \\
\hline Anthropological-cultural Area & 8 & 0 \\
\hline Other Scientific-disciplinary Areas & 24 & 48 \\
\hline By choice & 16 & 12 \\
\hline Workshops & 6 & 0 \\
\hline Other knowledge & 9 & 14 \\
\hline Internship & 9 & 10 \\
\hline Final test & 4 & 6 \\
\hline Total UTC & 180 & 180 \\
\hline
\end{tabular}


The course in Bologna shows a greater concentration of training activities in the pedagogy sector, it includes cultural anthropology and some laboratory activities. The LUMSA course offers a greater number of credits in non socio-psycho-pedagogical sectors, in which it includes two teachings in the philosophical area. The laboratory dimension cannot be appreciated using the table, while credits related to knowledge of theological nature come to light. Both courses appear to provide a solid and specific preparation for early childhood educators.

Among the 11 campuses that have established within the L-19 courses a specific address to educators for age 0 to 3 , we consider, rather arbitrarily, only three examples for this study, they are related with the big areas of the national territory, North, Centre, South (Table 2).

Table 2 - University training credits (UTC) for disciplinary areas for undergraduate courses with a specific address to educators for age 0 to 3

\begin{tabular}{|l|c|c|c|}
\hline Disciplinary Areas & $\begin{array}{c}\text { Bergamo } \\
\text { University } \\
\text { (UTC) }\end{array}$ & $\begin{array}{c}\text { Macerata } \\
\text { University } \\
\text { (UTC) }\end{array}$ & $\begin{array}{c}\text { Catania } \\
\text { University } \\
\text { (UTC) }\end{array}$ \\
\hline Pedagogical Area & 50 & 64 & 61 \\
\hline Psychological Area & 20 & 16 & 16 \\
\hline Sociological Area & 10 & 8 & 10 \\
\hline Anthropological-cultural Area & 0 & 0 & 0 \\
\hline Other Scientific-disciplinary Areas & 60 & 56 & 66 \\
\hline By choice & 15 & 16 & 12 \\
\hline Workshops & 0 & 0 & 0 \\
\hline Other knowledge & 10 & 0 & 3 \\
\hline Internship & 10 & 12 & 9 \\
\hline Final test & 5 & 8 & 3 \\
\hline Total UTC & 180 & 180 & 180 \\
\hline
\end{tabular}

We may observe that the three courses that activated a specific address do not show relevant differences. Nevertheless, some differences appear, like the higher number of credits offered by the University of Macerata in the pedagogical field, especially if compared to Bergamo. Conversely, concerning other disciplinary sectors that include sciences of varied nature, from medical to historical and linguistic, Catania shows a more articulated proposal. The University of Bergamo offers the possibility to develop other knowledge useful 
for insertion on the labour market, so does Catania but in a minor way, while this possibility does not surface in the educational proposal of Macerata. On the other hand, the latter maintains a special emphasis on internship and the final test, whose amounts of credit are, for both disciplines, higher than in the other two universities analysed. We emphasize that the data about the three courses do not show the workshop activities and the teachings in the anthropological-cultural area. In general, the offers appear substantially effective to form the educators for early childhood services.

Finally, as emphasized above, most of the courses of the L-19 class are of the generic type. Table 3 below illustrates three cases, which once again are based on the geographic location criterion, we stress that the choice made does not have the intent of being representative in any way of the present offer in the respective contexts, it only intends to show some elements of reflection.

Table 3 - University training credits (UTC) for disciplinary areas for undergraduate courses of the generic type

\begin{tabular}{|l|c|c|c|}
\hline Disciplinary Areas & $\begin{array}{c}\text { Milan- } \\
\text { Bicocca } \\
\text { University } \\
\text { (UTC) }\end{array}$ & $\begin{array}{c}\text { Chieti } \\
\text { University } \\
\text { (UTC) }\end{array}$ & $\begin{array}{c}\text { Bari } \\
\text { University } \\
\text { (UTC) }\end{array}$ \\
\hline Pedagogical Area & $64^{*}$ & 66 & 75 \\
\hline Psychological Area & 8 & 0 & 12 \\
\hline Sociological Area & 12 & 0 & 12 \\
\hline Anthropological-cultural Area & 8 & 0 & 0 \\
\hline Other Scientific-disciplinary Areas & 40 & 84 & 51 \\
\hline By choice & 24 & 12 & 12 \\
\hline Workshops & 0 & 0 & $3^{\text {** }}$ \\
\hline Other knowledge & 0 & 0 & 0 \\
\hline Informatics and online skills & 3 & 0 & $0^{\text {*** }}$ \\
\hline Foreign Language & 3 & 3 & 0 **** \\
\hline Internship & 10 & 6 & 9 \\
\hline Final test & 8 & 9 & 6 \\
\hline Total UTC & 180 & 180 & 180 \\
\hline
\end{tabular}

* Of which 6 UTC titled M/PED 01 interdisciplinary workshop

** It is an informatics workshop

*** Informatics and online skills are included in the workshop

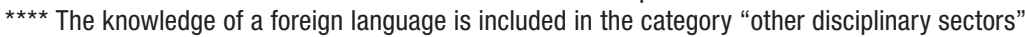


In general, the data present in the table lead us to remark the centrality taken by the pedagogical area in the training offer, especially in the Universities of Bari and Chieti, while Milan shows a comparatively lower number of credits but covers disciplinary areas that do not exist in the other two courses. Overall, we can affirm that, beside some differences, the proposals of Milan-Bicocca and Bari are quite similar, even considering that each assigns some of the knowledge to different disciplinary contexts (for example, the interdisciplinary workshop of Milan is assigned to the sector M/ PED 01 and not to the workshop activities, while the University of Bari puts the knowledge of a foreign language in the sector L-LIN/12 to the contrary of Chieti and Milan) and shows slightly different numbers of credits within the same disciplinary fields (apart from the sociological area where the number of credits coincides). The anthropological-cultural sector is instead a near total exclusivity of Milan-Bicocca. In brief, considering the three proposals, the one of the University of Chieti results the "weakest" of the three in assuring the necessary skills for those who work in nurseries: in fact, the offer includes a smaller number of disciplinary areas; the evident quantity of credits grouped under the invoice "other scientific disciplinary areas" (which was put in this paper to simplify the overall analysis of the various teaching courses) points to the attitude of the course to include different teachings that do not belong to the psycho-pedagogical-didactic context, and to recognise the relative centrality of the internship experience. Such critical issues concern elements that undoubtedly constitute the "core" of the training route to develop the figure of the educator for early childhood services.

\section{Conclusions}

The reflections that follow do not intend to exhaust the topic; they rather put the emphasis on some elements that would require further treatment in a different study.

In general, the three typologies of courses of study considered in this brief analysis do not diverge significantly from the proposals of Puglisi's amendment and by MIUR; however, it is necessary to highlight some differences. In fact, for the specialised courses of the University of Bologna of Rome, we can affirm that the overall training structure answers the criteria requested by the two institutional proposals referred in this paper. Concerning the courses that include a specific curriculum for the figure of the educator of early childhood services, the credits are usually assigned to the disciplinary areas mentioned above, which in this case too provide a good specific training. However, such considerations do not apply to the courses of generic type, as far as was 
possible to see using the examples provided above, these courses show some important differences on the national territory concerning the hypotheses of a training curriculum for the educators for age 0 to 3 , with consequences on the overall possibility to provide the professional profile that we discuss here.

Specifically, among the important disciplinary areas that appear weak - if not completely absent - in terms of training credits, there seem to be those of psychological and socio-pedagogical nature.

This determines a competence gap in the profile of the educator in relation to the skills expected and highlighted by national and international studies in the context of the early childhood education. In this context, the metacognitive knowledge for the profession of educator is provided by the disciplines of educational sciences and is assuming an increasingly strategic role within the scope of the individual and social empowerment.

Such skills are and must be intended as the capability of handling knowledge and optimise individual resources according to the reflection on learning in a constant search of meaning, which demands to be able to read and understand the different individual components of the child (cognitive, affective-motivational), to analyse its socio-cultural dimensions and to accompany its diachronic development. Finally, only the competences of the educational sciences appear to be able to grant the profile of an educator capable to understand how the learning process happens in a given context, in an ecological and situated perspective that underlines the relation of the individual and the groups of individuals among themselves and with the environment through which knowledge and experience are created (Bateson, 1976; Bronfenbrenner \& Morris, 2007).

A cross-sectional recommendation for the three typologies offered is to reinforce the centrality of the internship and the workshop activities, because they represent the characterising elements of a university curriculum that builds competence (Baldacci, 2010), consequently, increasingly oriented to develop professional skills starting from the experience and the reflection on the experience (Schön, 2006). Furthermore, the workshop approach, internship and final tests, especially if proposed as project work, represent a fundamental attempt to continue to facilitate the convergence of the academic preparation with the labour market, aiming to plan and implement training courses where theory and practice would be dialoguing all the time through a learningreflexive attitude that contributes to define an effectively useful professional profile in the educational contexts of destiny. Pursuing such perspective implies contemplating and reinforcing the role of the tutor inside the courses of study, especially in the direct or indirect internship: the tutor is an educative figure who embodies a central function escorting the students in the process of 
reflection on the practice, elaborating the entire theoretical-practical experience and building professional competence through a continued dialectic between the university and the different educational communities of implementation (Magnoler, 2015).

\section{References}

Baldacci M. (2010). Curricolo e competenze. Milano: Mondadori.

Bateson G. (1972). Verso un'ecologia della mente. Milano: Adelphi, 1977.

Bronfenbrenner U., Morris P.A. (2007). The Bioecological Model of Human Development. Handbook of Child Psychology. I:14.

Caroli D. (2014). Per una storia dell'asilo nido in Europa tra Ottocento e Novecento. Milano: FrancoAngeli.

European Commission-Eacea-Euridyce-Eurostat (2014). Key Data on Early Childhood Education and Care in Europe. 2014 Edition. Eurydice and Eurostat Report. Luxembourg: Publications Office of the European Union.

Lazzari A., Picchio M., Balduzzi L. (2015). Professionalization policies in ECEC field: trends and tensions in Italian Context. In International Journal Early Years Education (23), 3. 5. London: Routledge.

Magnoler P. (2015). Accompagnare, orientare, monitorare. Il tutor dei tirocinanti. In Tutor e Mentoring in Education. Pisa: Edizioni ETS, pp. 183-197.

OECD (2006). Starting Strong II: Early Childhood Education and Care. Paris, France: Organisation for Economic Development.

Peeters J. (2008). The construction of a new profession, A European Perspective on Professionalism in early Childhood Education. Amsterdam: SWP Publishers.

Peeters J., Urban M., Vandenbroeck M. (2016). Lessons learnt and a debate to be continued. In Vandenbroeck M., Urban M., Peeters J. (eds.), Pathways to professionalism in early childhood education and care. London: Routledge, pp. 132136.

Pirard F. (2011). From the curriculum framework to its dissemination: the accompaniment of educational practices in care facilities for children under three years. In European Early Childhood Education Research Journal, 2 (9), pp. 253266.

Restiglian E. (2017). La formazione iniziale degli educatori della prima infanzia. Realtà e prospettive. Bergamo: Zeroseiup edizioni.

Schön D.A. (1987). Formare il professionista riflessivo. Milano: FrancoAngeli, 2006.

Urban M. (2008). Dealing with Uncertainty: challenges and possibilities for the Early Childhood profession. In European Early Childhood Education Research Journal, 16 (2), pp. 135-152.

Urban M., Vandenbroeck M., Peeters J., Lazzari A., Van Laere K. (2011). CoRe: Competence Requirements in Early Childhood Education and Care. Research Documents. Brussels: European Commission. 
Urban M., Vandenbroeck M., Van Laere K., Lazzari A., Peeters J. (2012). Towards competent systems in early childhood education and care. Implications for policies and practice. In European Journal of Education, 47 (4), pp. 508-526.

Wenger E. (1998). Comunità di pratica. Apprendimento, significato e identità. Milano: Raffaello Cortina, 2006. 